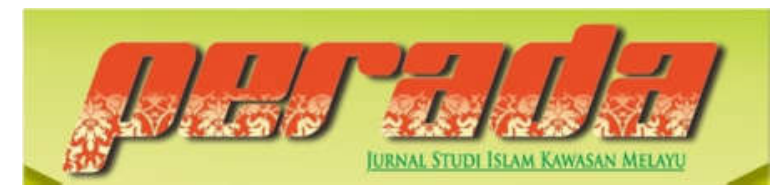

Perada: Jurnal Studi Islam Kawasan Melayu

ISSN 2656-7202 (P) ISSN 2655-6626 (0)

Volume 3 Nomor 1, Januari-Juni 2020

DOI: https://doi.org/10.35961/perada.v4i1.387

\title{
TINJAUAN HUKUM ISLAM TERHADAP MAHAR 10 TAIL AMAS UTANG DI KECAMATAN TELUK BINTAN KABUPATEN BINTAN
}

\author{
Indriani Agustin \\ STAIN Sultan Abdurrahman Kepulauan Riau \\ indriani11@gmail.com
}

\begin{abstract}
ABSTRAK
Artikel ini bertujuan untuk mengupas tentang tradisi pelaksanaan Mahar 10 Tail Amas Utang dalam tradisi masyarakat di Kecamatan Teluk Bintan. Penelitian ini merupakan penelitian hukum Islam dengan pendekatan antropologi. Dalam penelitian ini ditemukan praktik Mahar 10 Tail Amas Utang ini merupakan mahar adat melayu Bintan yang telah dilakukan secara turun menurun dan berlaku untuk orang-orang yang masih memiliki keturunan dengan raja. Mahar 10 tail amas utang adalah sebuah keihklasan dengan arti tail (timbangan orang zaman dulu dan biasa disebut kati), sedangkan amas memiliki arti (suka sama suka, ikhlas sama ikhlas). Dan mahar ini diaplikasikan dimasyarakat dengan keadaan yang tidak memiliki bentuk sebab telah diikhlaskan. Masyarakat di sana menganggap jika maharnya berbentuk uang, emas, seperangkat alat sholat atau Al-Qur'an maka semua itu tidak masuk akal, sebab beranggapan murah sekali harga perempuan bisa dibayar dengan sebuah benda, masyarakat di sana tidak mau menjualbelikan anak. Berdasarkan analisa menggunakan teori urf, diketahui bahwa praktik mahar 10 tail amas utang yang ada di Kecamatan Teluk Bintan tidak sah menurut 'urf dan juga persyaratan mahar sebagaimana dalam fikih munakahat. Dalam praktiknya, diketahui bahwa pihak Kantor Urusan Agama (KUA) kemudian mengambil solusi dengan mengganti Mahar 10 Tail Amas Utang dengan sebentuk cincin emas atau yang lainnya atau yang sering disebut juga mahal mitsil.
\end{abstract}

This article aims to explore the tradition of implementing the 10 Tail Amas Debt Mahar in the community tradition of Teluk Bintan District. This research is an Islamic law research with an anthropological approach. In this study, it was found that the 10 Tail Amas Debt dowry practice is a traditional Malay Bintan dowry that has been carried out for generations and applies to people who still have descendants with the king. The dowry of 10 tails of debt amas is a sincerity with the meaning of tail (the scales of the ancients and commonly called kati), while amas has the meaning (like and like, sincere and sincere). And this dowry is applied in society with conditions that do not have a form because it has been sincere. The people there think that if the dowry is in the form of money, gold, a set of prayer tools or the Koran then all of that doesn't make sense, because they think that the price for women can be paid with an object, the people there don't want to buy and sell children. Based on the analysis using the urf theory, it is known that the practice of dowry of 10 tails of debt in Teluk Bintan District is not legal according to 'urf and also the dowry requirements as in the munakahat figh. In practice, it is 
known that the Kantor Urusan Agama (KUA) then took a solution by replacing the 10 Tail Amas utang with a gold ring or something else or what is often called an mahar mitsil.

Kata Kunci: mahar, 10 tail amas, tradisi pernikahan, Bintan

\section{PENDAHULUAN}

Indonesia memiliki keberagaman adat istiadat, salah satunya yaitu adat dalam perkawinan, semua hal tentang perkawinan telah dijelaskan dalam Islam yang salah satunya yaitu tentang mahar, mahar adalah bentuk pemberian atau hadiah yang diberikan oleh mempelai laki-laki pada waktu akad nikah. Mahar ini adalah sesuatu yang dapat menaburkan benih cinta dalam memulai kehidupan yang baru. Dan pemberian ini sesuai dengan kemampuan yang memberi, karena itu tidak terlarang jika pemberian itu sedikit ataupun banyak, selama masih dalam batas-batas kemam-puan. Bagaimanapun, maka mahar adalah sesuatu yang pasti dan tidak boleh pihak wanita dihalangi untuk mendapatkannya. ${ }^{1}$ Sebagaimana Allah berfirman dalam QS. An-Nisa': 4

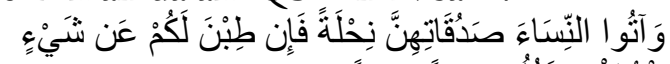

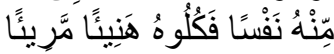

Artinya: "Berikanlah maskawin (mahar) kepada wanita (yang kamu nikabi) sebagai pemberian dengan penub kerelaan. Kemudian jika mereka menyerabkan kepada kamu sebagian dari maskawin itu dengan senang hati, maka makanlah (ambillah) pemberian itu (sebagai makanan) yang sedap lagi baik akibatnya."

Hukum memberi mahar adalah wajib dalam arti laki-laki yang hendak menikahi seorang perempuan harus menyerahkan mahar kepada istrinya dan berdosa apabila suami tidak meyerahkan

1 Abdul Halim Abu Syuqqah, Kebebasan Wanita, (Jakarta: Gema Insani Press, 1998), Penerjemah, As'ad Yasin, cet, ke-1, hlm. 84.

2 Departemen Agama RI, Al-Qur'an dan Terjemahan: Juz 1-30, Jakarta: Kumudasmoro Grafindo, Semarang, 1994). mahar kepada istrinya. ${ }^{3}$ Mahar terbagi menjadi dua yaitu: mahar musamma, bila mahar tidak disebutkan pada waktu akad, maka kewajibannya itu harus ditunaikannya selama masa perkawinan sampai putus perkawinan dalam bentuk kematian atau perceraian. Kemudian mahar mitsil adalah bila mahar tidak disebutkan jenis dan jumlahnya, maka kewajibannya adalah sebesar mahar yang diterima oleh perempuan lain dalam keluarganya. Mahar merupakan salah satu syarat sah dalam perkawinan yang tidak boleh ditiadakan.

Dari pembahasan diatas, ada satu kasus yang penulis dapat tentang mahar yang diaplikasikan oleh kalangan masyarakat di Kecamatan Teluk Bintan, yaitu menggunakan mahar 10 tail amas utang. Secara istilah mahar 10 tail merupakan sebuah timbangan pada zaman dahulu yang biasa disebut kati, sedangkan amas merupakan sudi sama sudi ikhlas sama ikhlas, oleh karena itu tidak dapat dinilaikan dengan uang dan tidak dapat dibayar, karena jika dibayar maknanya putus hubungan, maka dari itu disebutlah mahar 10 tail amas utang, masyarakat Kecamatan Teluk Bintan menganggap mahar dengan bentuk uang, perhiasan, seperangkat alat sholat, Al-Qur'an dan lain sebagainya dianggap tidak masuk akal karena mahar tersebut sama saja dengan menjual belikan anak. ${ }^{4}$

Dalam hal ini terdapat beberapa data yang tercatat di KUA terkait mempelai yang menggunakan mahar 10 tail amas utang yaitu, Muhammad Rusli dan Aisyah dengan No. Akta Nikah

${ }^{3}$ Amir Syarifuddin, Hukum Perkawinan Islam di Indonesia (Jakarta: kencana, 2007). hlm, 85.

${ }^{4}$ Johan, Tokoh Masyarakat Desa Penaga, 15 Juli 2020. 
(0084/008/XI/2018), Sandi Irawan dan Fauziah S.IP dengan No. Akta Nikah (0006/006/I/2018), Jasman dan Noverma Sari dengan No. Akta Nikah (0036/002/VI/2018), Masnur dan Surya dengan No. Akta Nikah (0060/012/VIII/2018), Marjoni dan Rayanti dengan No. Akta Nikah (0063/002/IX/2018). ${ }^{5}$

Berangkat dari fenomena tersebut, maka penelitian ini hendak mengupas tentang apa dan bagaimana praktik pemberian mahal 10 Tail Amas utang yang dipraktik di masyarakat Bintan tersebut serta bagaimana perspektif hukum Islam menilai praktik tersebut.

Untuk menjawab permasalah tersebut, maka menggunakan pendekatan normatif antropoligis dengan mewawancarai pihak-pihak terkait, dari pelaku, tokoh masyarakat dan juga tokoh agama. Data dari lapangan kemudian dianalisa mengujnakan teori urf dalam hukum Islam.

\section{TRADISI MAHAL 10 TAIL DI TELUK BINTAN}

Desa Bintan Buyu Kecamatan Teluk Bintan, Kabupaten Bintan (Kepri) dikenal sebagai pusat sejarah dan budaya. Dulunya daerah ini menjadi pusat Kerajaan Bentan, yang kemudian berlanjut dengan berdirinya kerajaan di Temasik sebelum berdirinya Kerajaan Malaka. Kerajaan Malaka di zaman Sultan Mahmud I pernah berpusat di Bintan, tepatnya di daerah yang hari ini bernama Desa Bintan Buyu. Di desa ini banyak ditemukan belasan makam bersejarah yang terpusat di kampung Bukit Batu dan Bintan Bekapur. ${ }^{6}$

Tidak hanya kaya dengan potensi cagar budaya, Bintan Buyu juga kaya

\footnotetext{
${ }^{5}$ Tim Penulis, Kantor Urusan Agama Kecamatan Teluk Bintan, (Bintan, 2020).

https://kebudayaan.kemdikbud.go.id/bpnbkepri/1 0-tahil-amas-dibayar-utang-mahar-nikah-unik-dibintan-buyu/
}

potensi nilai budaya. Sebagai daerah lama, sejumlah tradisi masyarakatnya masih lestari hingga saat ini. Tradisi masyarakatnya ada yang berbeda dengan masyarakat Melayu lainnya yang ada di Provinsi Kepri, khususnya dengan masyarakat Bintan lainnya. Hal ini bisa terlihat dalam acara pernikahan masyarakat Melayu yang ada di Kecamatan Teluk Bintan, khususnya Desa Bintan Buyu, Bintan Enau, Bintan Bekapur, dan Bintan Bukit Batu. ${ }^{7}$

Mahar atau maskawin dalam pernikahan di empat desa yang ada di Kecamatan Teluk Bintan cukup unik. Maharnya yaitu 10 tail amas dibayar utang. Mahar ini sudah berlangsung turun temurun dalam masyarakat tersebut. Amas yang disebut dalam mahar ini nilainya bukan sebesar emas murni yang ada di pasaran. "Amas itu kami sebut Emas Melayu, bukan emas murni. Dalam adat memang mahar ini dibayar utang, tak boleh tunai. Bagaimana pengantin laki-laki membayarnya, itu urusan mereka berdua setelab nikah. Antara pengantin laki-laki dan wanita."

Ia menyebut mahar seperti ini hanya berlaku di empat kampung yang dulunya masuk wilayah Kepenguluan Bintan Buyu meliputi Bintan Enau, Bintan Bukit Bukit Batu, Bintan Buyu dan Bintan Bekapur. Sementara, kampung-kampung yang lain yang bertetangga, seperti Desa Penaga, mas kawinnya berbeda dengan Bintan Buyu. "Kami 10 tail amas, mereka 7 tail amas". Sedangkan yang penulis temukan berbeda dari pembahasan di atas karena karena Desa Penaga juga menggunakan mahar 10 tail amas utang, hal ini hanya berbeda pemahaman disetiap desa serta mengaplikasian dalam masyarakatnya saja.

Hal menarik sesuai perkembangan zaman, mahar itu juga mengalami perubahan. Dulunya hanya 10 tail amas dibayar utang, kini mengalami perubahan. Maharnya berubah menjadi 10 tail amas

${ }^{7}$ Ibid. 
dibayar utang berganti sebentuk cincin emas dibayar tunai. Penyesuaian ini menyesuaikan dengan kondisi perkembangan zaman, termasuk administrasi pernikahan di Kantor Urusan Agama (KUA) yang berwenangan mencatat pernikahan.

Selain mahar nikah, di Desa Bintan Buyu juga ada keunikan dalam acara tepuk tepung tawar. Tak semua orang boleh melakukan tepuk tepung tawar. Hanya 9 orang yang boleh melakukan tepung tepung tawar dan semuanya laki-laki. Mereka adalah penghulu (kepala desa), waris pengantin laki-laki, waris pengantin wanita, walak pengantin laki-laki dan walak pengantin wanita. Selain itu juga yang berhak tukang doa (lebai), tuan said, juru kunci kampung (orang yang dituakan), dan mudim mak andam. Kemudian dalam pemberian cincin untuk gadis berbeda bentuk dengan perempuan yang pernah menikah (janda), seorang gadis bentuk cincinnya harus belah rotan (tanpa ada ukiran ataupun mutiara), sedangkan untuk janda boleh saja dengan model apapun. Di desa penaga ada kebiasaan yang selalu dilakukan oleh sepasang pengantin laki-laki dan perempuan sebelum mereka naik ke atas ranjang pengantin laki-laki izin kepada ayah perempuan "mohon izin pak malam ini saya akan naik ke atas ranjang, semoga bapak merestui ${ }^{\prime 8}$

Mahar 10 tail amas utang adalah sebuah keihklasan dengan arti tail (timbangan orang zaman dulu dan biasa disebut kati), jika dinilaikan dalam hitungan masa saat ini satu kati berkisaran $61 / 4$ ons, 1 ons bernilai 37,8 gram sesuai dengan KBBI. sedangkan amas memiliki arti emas melayu bukan emas murni namun ada juga pendapat lain mengenai amas yaitu "suka sama suka, ikhlas sama ikhlas" sebagaimana penjelasan langsung dari tokoh adat di desa penanga. ${ }^{9}$ Dan mahar ini diaplikasikan dimasyarakat

\footnotetext{
${ }^{8}$ Johan, Wawancara. Juli 2020

${ }^{9}$ Ibid.
}

dengan keadaan yang tidak memiliki bentuk sebab telah diikhlaskan. ${ }^{10}$

Masyarakat disana menganggap jika maharnya berbentuk uang, emas, seperangkat alat sholat atau Al-Qur'an maka semua itu tidak masuk akal, sebab beranggapan murah sekali harga perempuan bisa dibayar dengan sebuah benda, nah masyarakat disana tidak mau menjual belikan anak. ${ }^{11}$

Sebagaimana penjelasan dari tokoh agama/adat didesa penaga, bintan buyu, dan pengujan dibawah ini, mereka mengatakan:

Johan mengatakan, "mahar tidak dapat dibayar dengan uang ataupun benda lainnya, Sebab jika maharnya dalam bentuke uang, emas, seperangkeat alat sholat, Al-Qur'an, dan benda lainnya dianggap tidak masuk akal, karena kami mengaggap murah sekali harga perempuan jika dinilaikan dengan benda. Mahar adat bintan (desa penaga) dibayar dengan sebuah kerelaan (sudi sama sudi ikblas sama ikblas, karena pernikahan itu selamanya sampai mati, oleh sebab itu adanya mahar ini bertujuan agar perkawinan kekal abadi. Apabila 10 tail amas utang itu dibayar maka jatubnya putus bubungan pernikahan (talak).,"12

Idrus menyebutkan bahwa, "Tidak semua masyarakat Bintan memakai mabar 10 tail amas utang, karena mabar tersebut biasa digunakan untuk orang-orang yang masib memiliki garis keturunan raja". 13 Demikian juga diakui oleh Ayu dan Rosita.

Bidin mengatakan, "Mahar 10 tail amas utang biasa dipakai oleh orang-orang tinggi seperti keturunan raja. Kalo masyarakat biasa saja pakai uang dolar atau ringgit. Orang dulu juga ada yang beranggapan tidak boleh mahar dalam bentuk emas, karena emas dapat dijual, sedangkan pemahaman orang zaman dulu mahar itu tidak boleb dijual bagaimanapun keadaannya, orang zaman dulu meyakini apabila

\footnotetext{
${ }^{10}$ Ibid.

${ }^{11}$ Ibid.

${ }^{12}$ Johan, Wawancara, Juli 2020, 15:30 WIB

13 Idrus, Ayu, Rosita, Wawancara, Rabu, 9 September 2020 Pukul 13:50 WIB.
} 
mahar dijual akan merusak kebahagiaan rumah tangga yang menimbulkan masalah-masalab dalam keluarga bahkan perpisahan"."

Apan menceritakan, "mahar 10 tail amas utang ini dibayar dengan "ikblas" dalam arti lain tidak ada wujudnya, kata ikblas itu terucap setelah ada kata sab, dan sebenarnya mabar 10 tail amas utang ini hanya sebuah kalimat yang mengartikan babwasannya kedua mempelai telah melakukan nikah batin, yang akan dilakukan pada saat malam pertama oleh kedua mempelai., 15

Demikian juga pendapat pasangan, Amri dan Santi, yakni "mahar 10 tail amas utang biasa dipakai untuk orang-orang yang memiliki keturunan raja, dan kebanyakan dari kami juga kurang memahami tentang mahar tersebut, karena kami hanya mengikuti apa yang orangtua kami inginkan"

Nikah batin adalah pernikahan yang dilakukan oleh seorang mempelai laki-laki dengan seorang mempelai perempuan pada malam pertama sebelum melakukan hubungan suami istri. Nikah batin ini mencontoh kepada nikahnya Adam dan Hawa dimana Allah sebagai walinya dan malaikat sebagai saksi. ${ }^{16}$ Dalam Islam setelah tersebutnya akad (ijab dan qabul) berarti seseorang itu telah menikah secara lahir dan batin, dan tidak perlu adanya lagi pernikahan secara batin.

\section{MAHAR 10 TAIL AMAS UTANG DALAM TINJAUAN HUKUM ISLAM}

Penggunaan Mahar 10 Tail amas utang dalam perkawinan adat masyarakat kecamatan teluk bintan telah ada sejak dahulu dan masih dilaksanakan hingga saat ini. Apabila fenomena tersebut dikaitkan dengan hukum Islam tidak lepas dari

${ }^{14}$ Bidin, Wawancara, Rabu, 9 September 2020 Pukul 14:17 WIB.

15 Apan, Wawancara, Rabu, 9 September 2020 Pukul 16:09 WIB.

16

bttps:// ejournal.uinib.ac.id/jurnal/index.php/turast/artic le/view/36. mahar menurut Islam dan 'urf. Mahar atau maskawin dalam Al-Qur'an telah dijelaskan bahwa wajib seorang pengantin laki-laki memberi mahar kepada perempuan yang akan dia nikahi. Allah berfirman dalam QS. An-Nisa': 4.

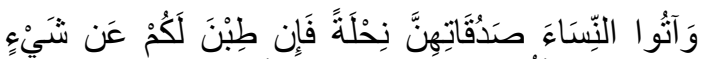

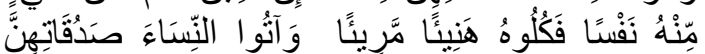

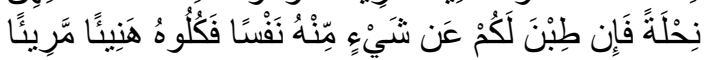
"Dan berikanlab maskawin (mahar) kepada perempuan (yang kamu nikahi) sebagai pemberian yang penub kerelaan. Kemudian, jika mereka menyerabkan kepada kamu sebagian dari (maskawin) itu dengan senang hati, maka terimalah dan nikmatilah pemberian itu dengan senang hati".'17

Mahar dalam Islam merupakan salah satu rukun dan syarat sahnya suatu perkawinan, sehingga untuk dikatakan sah sebuah perkawinan tentunya harus memenuhi syarat-syarat tertentu. Imam Syafi'i memberikan definisi yang terbuka dan jelas tentang mahar yaitu, sesuatu (bisa harta maupun jasa) yang wajib diberikan oleh suami kepada istri untuk menghalalkan seluruh anggota badannya, yaitu asalkan sesuatu yang dijadikan mahar itu bernilai dan berharga, maka boleh digunakan sebagai mahar atau maskawin, maka jelas bahwa mahar baik berupa jasa atau manfaat (non materi) diperbolehkan.

Sebagaimana dalam kitab al-umm, syafi'i mengatakan bahwa Setiap barang yang bisa dijual atau disewakan dengan suatu harga, maka barang tersebut bisa dijadikan mahar. Sebaliknya bila barang itu tidak mempunyai harga dan tidak bisa dijual, maka barang tersebut tidak layak menjadi mahar.

Pendapat Syafi'i tentang kebolehan perempuan menikah, dengan mahar lelaki itu menjahit kepadanya pakaian atau membangun baginya rumah atau melayaninya sebulan atau baginya laki-laki

${ }^{17}$ Departemen Agama RI, Al-Qur'an dan Terjemahan: Juz 1-30, Jakarta: Kumudasmoro Grafindo, Semarang, 1994). 
itu buat suatu perbuatan apa saja atau ia mengajarkan al-Qur'an, dalam kitabnya alUmm Syafi'i berkata,"boleh, bahwa wanita itu mengawini seorang laki-laki untuk menjabit kepadanya pakaian atau membangun baginya rumah atau melayani sebulan atan lelaki itu berbuat baginya suatu perbuatan apa saja atau ia mengajarkan al-Qur'an yang disebutkan atau ia mengajarkan bagi wanita itu seorang budak dan yang serupa dengan ini.

Penjelasan dari kitab di atas bahwa Imam Syafi'i membolehkan adanya mahar dengan menjahit pakaian, membangun rumah, melayani sebulan, atau mengajarkan al-Qur'an kepada istri, yang merupakan mahar jasa. Menurut Imam Syafi'i, setiap manfaat yang dimiliki dan halal harganya serta mempunyai nilai kesederhanaan pada mahar itu lebih beliau sukai. Beliau memandang sunnah, bahwa tidak berlebih pada mahar.

Hadits yang dijadikan argumentasi Imam Syafi'i mengenai mengenai mahar jasa adalah, "Sesunggubnya Rasulullah $S A W$ bersabda: "Bayarlab olehmu, alaiq" (istilah lain untuk mabar). Apakab, 'alaiq itu $Y a$ Rasulullab? Nabi menjawab: "sesuatu yang disenangi oleh keluarga wanita". (HR. Abu Dawud dan Tabrani). ${ }^{18}$

Ulama Syafi'iyah mengatakan mahar manfaat adalah sah. Kaidahnya menurut mereka adalah setiap sesuatu yang dapat menjadi harga dalam jual beli dapat pula menjadi mahar, jika sah membeli rumah dengan harga berupa memanfaatkan suatu tanah pertanian selama waktu tertentu, maka begitu pula sah menjadikan manfaat tersebut sebagai mahar.

Setiap kegiatan yang diupah seperti mengajar al-Qur'an, fiqh dan sebagainya, atau mengajar keterampilan seperti bertenun, menjahit, atau menjahitkan pakaian, atau membangun rumah, atau melayani si perempuan, meski ia merdeka, maka semua itu sah untuk menjadi mahar,

${ }^{18}$ HR. Abu Dawud dan Tabrani seperti halnya sah untuk menjadi harga jual beli. Sebagaimana hadits di bawah ini: ${ }^{19}$

"Telah menceritakan kepada kami (Abdullah bin Maslamah) telah menceritakan kepada kami (Abdul Aziz bin Abdul Abu Hazim) dari (Ayahnya) bahwa dia mendengar (Sabl) berkata; seorang wanita datang kepada Nabi shallallabu 'alaibi wasallam dan berkata: "Saya datang kepada anda untuk menyerabkan diriku kepada anda, "Beliau lalu berdiri lama dan menelitinya dengan seksama, ketika beliau berdiri lama seorang laki-laki berkata: 'Wabai Rasulullah, jika anda tidak berkenan dengannya, maka nikabkanlah aku dengannya.' Rasulullah shallallahu 'alaibi wasallam bertanya kepada laki-laki tersebut: 'Apakah kamu mempunyai sesuatu yang dapat dijadikan mahar untuknya? 'Laki-laki itu menjawab: 'Tidak.' Beliau bersabda: 'Carilah terlebib dabulu.' Lalu laki-laki itu pergi, sesaat kemudian dia kembali dan berkata; Demi Allah, aku tidak mendapatkan sesuatupun.' Beliau bersabda: Pergi dan carilab lagi walaupun hanya dengan cincin dari besi.' Kemudian laki-laki itu pergi, tidak berapa lama dia kembali sambil berkata; 'Aku tidak mendapatkean apa-apa walau cincin dari besi.' Saat itu laki-laki tersebut tengah mengenakan kain sarung, lantas dia berkata; 'Aku akan menjadikan kain sarung ini sebagai mahar.' Maka Nabi shallallabu 'alaibi wasallam bersabda: Jika kamu memakaikan kain sarung itu padanya, maka kamu tidak memakai apa-apa, sementara jika kamu yang memakai sarung tersebut, dia tidak memakai apa-apa.' Laki-laki itu duduk termenung, ternyata Nabi shallallabu 'alaibi wasallam melibatnya berpaling, lalu beliau memerintabkan seseorang untuk memanggilnya, maka dipanggilah laki-laki tersebut, beliau bertanya: 'Apakah kamu mempunyai hafalan dari $A l$ Qur'an? 'Laki-laki itu menjawab; 'Ya, saya telah hafal surat ini dan ini.' Lalu beliau bersabda: Maka aku nikabkan kamu dengan wanita itu, dengan mahar apa yang telab engkau hafal dari surat Al Qur'an." (HR. Shahih Bukhari, No. 5422) $)^{20}$

${ }^{19}$ HR. Shahih Bukhari, No. 5422

${ }^{20}$ HR. Shahih Bukhari, No. 5422 
Dari gambaran definisi yang telah dipaparkan di atas dan dari hadits Rasulullah dapat di pahami bahwa mahar 10 tail amas utang yang berlaku di kecamatan teluk bintan tidak sesuai dengan syarat-syarat mahar dalam nash dan syari'ah, karena maharnya tidak jelas dan tidak dapat di wujudkan dengan sebuah benda, ataupun jasa. Menurut penulis sebuah mahar itu wajib diberikan kepada seorang istri sesuai dengan kemampuan laki-laki (tidak memberatkan) asalkan sesuai dalam syarat-syarat mahar tersebut sebagai hadiah atas kerelaan (ikhlas) seorang istri karena dinikahi dengan suaminya.

Dikaji berdasarkan Al-Qur'an terkait urf atau 'adab sebagaimana penejelasan dalam surah Al-A'raf ayat 199 "Jadilah engkau pemaaf dan surublah orang mengerjakan yang ma'ruf, serta berpalinglab dari pada orangorang yang bodoh." Yang dimaksud mengerjakan yang ma'ruf pada ayat di atas, yaitu mengerjakan kebiasaan yang baik yang tidak bertentangan dengan norma agama Islam serta dengan cara baik yang diterima oleh akal sehat dan kebiasaan manusia yang berlaku. Maka ayat tersebut dapat dipahami sebagai perintah untuk mengerjakan sesuatu yang telah dianggap baik sehingga telah menjadi tradisi dalam suatu masyarakat. Namun, yang terjadi di masyarakat banyak hal-hal yang dilakukan tidak berdasarkan Al-Qur'an sebagaimana mahar yang ada di daerah kecamatan teluk bintan. Sebaiknya menurut penulis hal semacam ini tidak layak untuk terus dilestarikan menjadi adat.

Selanjutnya kita telaah berdasarkan macam-macam 'urf. Pertama, ditinjau dari sisi kualitasnya, mahar 10 tail amas utang ini termasuk ke dalam 'urf fasid karena bertentangan dengan hukum syara' atau mengahalalkan yang haram dan mengharamkan yang halal, sebab telah jelas mahar tersebut hukumnya haram. Oleh karena itu menurut penulis sebaiknya masyarakat disana mengikuti prosedur syarat-syarat mahar yang telah ditetapkan dari Kantor Urusan Agama dengan mahar yang bermanfaat, berbentuk benda ataupun jasa agar tidak melanggar nash.

Kedua, ditinjau dari ruang lingkupnya, mahar ini termasuk ke dalam 'urf khash, karena penerapannya tidak terdapat diseluruh negeri atau seluruh kepulauan riau, namun mahar tersebut khusus di daerah Kecamatan Teluk Bintan. Oleh sebab itu, menurut penulis sebaiknya masyarakat melaksanakan hukum yang biasa digunakan oleh seluruh masyarakat, penulis tidak menayalahkan adat selagi tidak melanggar ketentuan yang telah ditetapkan dalam Al-Qur'an dan Sunnah.

Ketiga, 'urf ditinjau dari objeknya, mahar 10 tail amas utang termasuk dalam urf al-amali (perbuatan). Sebab sudah menjadi suatu kebiasaan yang turun menurun dari nenek moyang dalam menetapkan mahar ataupun maskawin. Menurut penulis sebaiknya masyarakat harus memahami Islam lebih dalam agar tidak salah dalam menafsirkan ayat-ayat Al-Qur'an dan Hadits, dan tidak mengatakan lagi bahwa ketentuan mahar menurut Al-Qur'an itu tidak masuk akal, sebab sama saja dengan menjual belikan anak. Padahal semua hal yang telah dituliskan dalam Al-Qur'an merupakan sebuah kebaikan wajib diikuti sebagai pedoman hidup semua umat manusia.

Menurut ulama ushul fiqh, 'urf bisa dijadikan pertimbangan dalam penetapan hukum syara' apabila memenuhi persyaratan-persyaratan tertentu, yaitu: Tidak ada dalil yang khusus untuk kasus tersebut baik dalam Al-Qur'an atau Sunnah, Pemakaiannya tidak mengakibatkan kesampingkannya nash syari'ah termasuk juga tidak mengakibatkan ke mafsadatan, kesempitan, dan kesulitan, dan terakhir telah berlaku secara umum dalam arti bukan hanya yang biasa dilakukan oleh beberapa orang saja. Nah, dalam pelaksanaan mahar 10 tail amas utang tersebut jelas mengesampingkan nash 
syari'ah dan juga mengakibatkan kemafsadatan, dan juga pelaksanaannya hanya dilakukan oleh orang-orang tertentu saja.

Mahar termasuk ke dalam syarat sah nikah, maka wajib adanya mahar yang sesuai dengan syarat-syarat menurut syariah, jika tidak ada wujudnya maka mahar dinyatakan batal, dan ini dapat menyebabkan rusaknya agama, karena pernikahannya tidak sah dan jatuhnya berzina, dalam memelihara keturunan jika nikahnya tidak sah maka otomatis anak yang dilahirkan juga anak hasil zina yang menyebabkan rusaknya keturunan dan terputusnya nasab, kemudian dalam memelihara harta tersebab rusaknya nasab yang menyebabkan terputusnya warisan bagi sang anak serta terputusnya wali dari ayahnya.

Kesimpulan analisis di atas maka batal pernikahan yang menggunakan mahar 10 tail amas utang yang ada dikecamatan teluk bintan, karena maharnya tidak sesuai dengan syarat-syarat mahar menurut islam, serta tidak sesuai dalam kajian 'Urf atau Al-'adahnya, oleh sebab itu pihak Kantor Urusan Agama di kecamatan teluk bintan mengeluarkan solusi kepada masyarakat agar tetap dapat melangsungkan pernikahan yang sah secara agama tapi tidak menghilangkan adat yang ada, adapun penjelasan serta solusinya yaitu:

Penjelasan dari Kepala Kantor Urusan Agama di Kecamatan Teluk Bintan mengenai mahar. Menurut Mulyadi, "dalam pernikahan mahar telah diatur dalam islam dan memiliki syarat-syaratnya, adapun syarat-syarat mahar tersebut yaitu, barangnya harus jelas bentuk dan wujudnya, memiliki manfaat, suci, bukan barang gasab, berharga, sedangkan mahar 10 tail amas utang itu tidak termasuk dalam kategori syarat mabar tersebut.,21

${ }^{21}$ Mulyadi, Wawancara, 11 September 2020 Pukul 10:45 WIB
Sedangkan Zainal Nahra, mengatakan, "dalam bukum Islam mahar itu boleh dalam bentuk utang atau tunai asalkan jelas bentuk atau wujudnya dan kapan dibayarnya. Untuk tercapainya tujuan dari pernikahan maka pakailah mahar mitsli atau mabar musamma. Dalam islam juga jumlah mabar tidak ada batas minimalnya tapi sesuai dengan kesanggupan calon mempelai laki-laki, ${ }^{22}$

Sebagai Kepala Kantor Urusan Agama (KUA) wajib memahami syaratsyarat mahar, untuk menghindari hal-hal kecil ataupun besar yang dapat membatalkan pernikahan. Oleh sebab itu, seperti yang dilakukan Kepala Kantor Urusan Agama di kecamatan teluk bintan dan juga mantan Kepala Kantor Urusan Agama yang pernah menjabat disana memberi solusi kepada masyarakat agar mengganti penyebutan mahar 10 tail amas utang ini diganti dengan sebentuk cincin emas, uang ataupun kalung secara tunai. Sebagai contoh :"Hai fulan, Aku nikabkan engkau dengan anak kandungku fulanah dengan mahar 10 tail amas utang." Maka kalimat tersebut diganti menjadi, "Hai fulan, Aku nikabkan engkau dengan anak kandungku Fulanah dengan mahar 10 tail amas utang DIGANTI dengan sebentuk cincin emas tunai."

Dengan adanya solusi yang di ambil dari Kepala Kantor Urusan Agama di kecamatan Teluk Bintan barulah pernikahan dapat dilaksanakan. Tujuannya agar pernikahan sah secara hukum dan adatpun tidak dihilangkan. Kejadian ini masih berlaku sampai saat ini, namun sebelum melangsungkan pernikahan kepala KUA terlebih dahulu mengarahkan kepada calon pengantin ataupun orang tuanya agar tidak lagi menggunakan mahar 10 tail amas utang.

\section{KESIMPULAN}

22 Zainal, Wawancara, 11 September 2020

Pukul 11:26 WIB 
Berdasarkan uraian dan analisa di atas, maka dapat ditarik beberapa kesimpulan. Pertama, mahar dalam Islam merupakan salah satu rukun dan syarat sahnya suatu perkawinan, sehingga untuk dikatakan sah sebuah perkawinan tentunya harus memenuhi syarat-syaratnya. Sedangkan, mahar 10 tail amas utang adalah sebuah keihklasan dengan arti tail (timbangan orang zaman dulu dan biasa disebut kati), jika dinilaikan dalam hitungan masa saat ini satu kati berkisaran $61 / 4$ ons, sedangkan amas memiliki arti (suka sama suka, ikhlas sama ikhlas). Dan mahar ini diterapkan masyarakat dengan keadaan yang tidak memiliki bentuk sebab telah diikhlaskan. Kedua, apabila ditinjau dari perspektif urf, maka apabila ditinjau dari ruang lingkupnya, mahar ini termasuk ke dalam 'urf khash, karena penerapannya tidak terdapat di seluruh negeri atau seluruh Kepulauan Riau, namun mahar tersebut khusus di daerah Kecamatan Teluk Bintan. Sedangkan bila ditinjau dari dari sisi kualitasnya, mahar 10 tail amas utang ini termasuk ke dalam 'urf fasid karena bertentangan dengan hukum syara' atau mengahalalkan yang haram dan mengaharamkan yang halal, sebab telah jelas mahar tersebut hukumnya haram. Apabila ditinjau berdasarkan objeknya, mahar 10 tail amas utang termasuk dalam urf al-amali (perbuatan). Sebab sudah menjadi suatu kebiasaan yang turun menurun dari nenek moyang dalam menetapkan mahar ataupun mas kawin. Apabila ditarik kesimpulan berdasarkan hal itu, maka pelaksanaan mahar 10 tail amas utang tersebut jelas mengesampingkan nash syari'ah dan juga mengakibatkan kemafsadatan, dan juga pelaksanaannya hanya dilakukan oleh orang-orang tertentu saja. Berdasarkan dari pada hal itu, dalam praktiknya, mahal 10 tail amas tersebut kemudian diganti menjadi mahal mitsli yang menjadi berupa cincin ataupun seperangkat alat salat dan ataupun benda lainnya yang digunakan sebagai mahar oleh mempelai. []

\section{DAFTAR PUSTAKA}

Alfaroby. (2010). Transformasi Pemahaman Masyarakat tentang Mahar dalam Adat Jambi (Studi Kasus Desa Penegah Kecamatan Pelawan Kabupaten Sarolangan), (Fakultas Syariah dan Hukum, Universitas Islam Negeri Syarif Hidayatullah Jakarta).

al-Ghazali, A. H. (n.d.). al-Mustafa Min Tlm al-Usul. Beirut: Dar al-Fikr.

Apan. (2020, September Rabu). Wawancara. (I. Agustina, Interviewer)

Arikunto, S. (2006). Prosedur Penelitian: Suatu Pendekatan Praktik. Jakarta: Rineka Cipta .

Ashari, I. (2016). Makna Mahar Adat dan Status Sosial Perempuan dalam Perkawinan di Desa Penengahan Kabupaten Lampung Selatan, (Fakultas Ilmu Sosial dan Ilmu Politik, Universitas Lampung).

as-Suyuti, I. J.-M. (n.d.). Tafsir Jalalain. Kairo: Dar al-Fikr.

Bagir, M. (2009). Fiqh Praktis II Menurut Al-Qur'an As Sunnah dan Pendapat Para Ulama. Jakarta: Karisma.

Bidin. (2020, September Rabu). Wawancara. (I. Agustina, Interviewer)

Ghazaly, A. (2006). Fiqh Munakahat. Jakarta: Kencana.

Hasan, M. A. (2006). Pedoman Hidup Berumah Tangga dalam Islam, Jakarta: , 
2006), . Jakarta: Siraja Penada Media Grup.

Hikmah, N. (2011). Implementasi Pemberian Mahar pada Masyarakat Suku Bugis dalam Perspektif Hukum Islam (Studi Kasus di Kelurahan Kalbaru Kecamatan Cilincing Jakarta Utara.

Idrus, A. R. (2020, September Rabu). Wawancara. (I. Agustina, Interviewer)

Irawan, H. (2006). Tinjauan Hukum Islam Terhadap Pemberian Mahar pada Adat Perkawinan di Kelurahan Kedaton Kabupaten Ogan Komering Ilir, (Fakultas Syariah UIN Raden Fatah Palembang).

Johan. (2020, Juli 20). Wawancara, Juli 2020, 15:30 WIB. (I. Agustina, Interviewer)

Kamal, M. A. (2007). Fiqh Sunnah Wanita. Jakarta: Pena Pundi Aksara.

Kamal, M. A. (2007). Fiqh Sunnah Wanita, (Jakarta: Pena Pundi Aksara, 2007). Jakarta: 2007.

Kholil, M. (1955). kembali kepada al-qur'an dan as-sunnab . Semarang: Bulan Bintang.

KUA, T. P. (2020). Profil Kantor Urusan Agama Kecamatan Teluk Bintan. Bintan.

Maisura. (2018). Penetapan mahar dalam pernikahan pada masyarakat gampong meunasah keude kecamatan Bandar baru kabupaten pidie jaya.

Manshur, A. Q. (2012). Buku Pintar Fikih Sunnah Wanita. Jakarta: Zaman.

Mughiyah, M. J. (2011). Fiqh Lima Mą̧ab: Ja'fari, Hanafi, maliki, Hambali, Penerjemah, Masykur A.B, Afif Mubammad, Idrus Al-Kaff. Jakarta: Lentera.

Mulyadi. (2020, September Jum'at). Mulyadi, Wawancara, 11 September 2020. (I. Agustina, Interviewer)

Mulyadi. (2020, September Jum'at). wawancara . (I. Agustina, Interviewer)

Nahra, Z. (2020, September Jum'at). Wawancara. (I. Agustina, Interviewer)
Penulis, T. (2020). Profil Kecamatan Teluk Bintan. Bintan.

RI, D. A. (1994). Al-Qur'an dan Terjemahan: Juг. 1-30. Jakarta: Kumudasmoro Grafindo.

Sahrani, T. d. (2010). Fiqh Munakahat, cet ke-2. Jakarta: PT. Raja Grafindo Persada.

Shomad, A. (2007). Hukum Islam Penormaan Prinsip Syariab dalam Hukum Indonesia. Jakarta: Kencana.

Slamet, A. (1999). Fiqib Munakahat I. Bandung: CV Pustaka Setia.

Syarifuddin, A. (2003). Garis-garis Besar Fiqh. Jakarta: Penada Media.

Syarifuddin, A. (2007). Hukum Perkawinan Islam di Indonesia. Jakarta: kencana.

Syarifuddin, A. (2008). Ushul Fiqh. Jakarta: Kencana.

Syarifuddin, A. (2008). Ushul figh . Jakarta: Logos Wacana Ilmu.

Syarifuddin, A. (2009). Hukum Perkawinan Islam di Indonesia antara Fiqh Munakahat dan UU Perkawinan. Jakarta: Kencana.

Syuqqah, A. H. (1998). Kebebasan Wanita. Jakarta: Gema Insani Press.

Yunus, M. (1990). Kamus Bahasa ArabIndonesia. Jakarta: Hidakarya Agung. 